\section{(A) Check for updates}

Cite this: Org. Biomol. Chem., 2017, 15,3717

\title{
Expanding the substrate scope of phenylalanine ammonia-lyase from Petroselinum crispum towards styrylalanines $\uparrow$
}

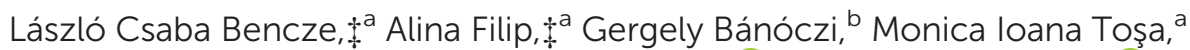 \\ Florin Dan Irimie, ${ }^{a}$ Ákos Gellért, ${ }^{c}$ László Poppe (D)*a,b,d and Csaba Paizs (D) *a
}

This study focuses on the expansion of the substrate scope of phenylalanine ammonia-lyase from Petroselinum crispum (PCPAL) towards the L-enantiomers of racemic styrylalanines rac-1a- $\mathbf{d}$ - which are less studied and synthetically challenging unnatural amino acids - by reshaping the aromatic binding pocket of the active site of PCPAL by point mutations. Ammonia elimination from L-styrylalanine (L-1a) catalyzed by non-mutated PCPAL (wt-PCPAL) took place with a 777-fold lower $k_{\text {cat }} / K_{\mathrm{M}}$ value than the deamination of the natural substrate, L-Phe. Computer modeling of the reactions catalyzed by wt-PCPAL indicated an unproductive and two major catalytically active conformations and detrimental interactions between the aromatic moiety of L-styrylalanine, L-1a, and the phenyl ring of the residue F137 in the aromatic binding region of the active site. Replacing the residue $\mathrm{F} 137$ by smaller hydrophobic residues resulted in a small mutant library (F137X-PCPAL, $X$ being $V$, A, and G), from which F137V-PCPAL could transform L-styrylalanine with comparable activity to that of the wt-PCPAL with L-Phe. Furthermore, F137V-PCPAL showed superior catalytic efficiency in the ammonia elimination reaction of several racemic styrylalanine derivatives $(r a c-1 \mathbf{a}-\mathbf{d})$ providing access to $D-\mathbf{1} \mathbf{a}-\mathbf{d}$ by kinetic resolution, even though the D-enantiomers proved to be reversible inhibitors. The enhanced catalytic efficiency of F137V-PCPAL towards racemic styrylalanines rac-1a-d could be rationalized by molecular modeling, indicating the more relaxed enzyme-substrate complexes and the promotion of conformations with higher catalytic activities as the main reasons. Unfortunately, ammonia addition onto the corresponding styrylacrylates $2 a-d$ failed with both wt-PCPAL and F137V-PcPAL. The low equilibrium constant of the ammonia addition, the poor ligand binding affinities of $\mathbf{2} \mathbf{a}-\mathbf{d}$, and the non-productive binding states of the unsatu-

Received 6th March 2017, Accepted 4th April 2017 DOI: $10.1039 / \mathrm{c} 7 \mathrm{ob00562h}$ rsc.li/obc rated ligands $\mathbf{2 a}-\mathbf{d}$ within the active sites of either wt-PCPAL or F137V-PCPAL - as indicated by molecular modeling - might be responsible for the inactivity of the PCPAL variants in the reverse reaction. Modeling predicted that the F137V mutation is beneficial for the KRs of 4-fluoro-, 4-cyano- and 4-bromostyrylalanines, but non-effective for the KR process of 4-trifluoromethylstyrylalanine.

\footnotetext{
${ }^{a}$ Biocatalysis and Biotransformation Research Centre, Faculty of Chemistry and Chemical Engineering, Babeș-Bolyai University of Cluj-Napoca, Arany János Str. 11, RO-400028 Cluj-Napoca, Romania. E-mail: paizs@chem.ubbcluj.ro ${ }^{b}$ Department of Organic Chemistry and Technology, Budapest University of Technology and Economics, Müegyetem rkp. 3, H-1111 Budapest, Hungary. E-mail: poppe@mail.bme.hu

${ }^{c}$ Agricultural Institute, Centre of Agricultural Research, Hungarian Academy of Sciences, Brunszvik u. 2, H-2462 Martonvásár, Hungary

${ }^{d}$ SynBiocat Ltd, Lövőház u. 19/1, H-1024 Budapest, Hungary

$\dagger$ Electronic supplementary information (ESI) available: Experimental details. See DOI: $10.1039 / \mathrm{c} 7 \mathrm{ob} 00562 \mathrm{~h}$

$\$$ These authors contributed equally to this work
}

\section{Introduction}

The synthesis of unnatural aromatic amino acids in an enantiopure form is still a challenge in synthetic chemistry, highlighted by the significant interest in these building blocks for the development of therapeutic peptides and proteins. ${ }^{1-3}$

Since phenylalanine - as a pharmacophore element - has an important role in biologically active peptides and proteins, the development of synthetic methods leading to sterically more demanding analogues of this amino acid has gained increased attention. ${ }^{4-7}$ An attractive enzymatic route for the synthesis of non-natural phenylalanine analogues is provided by aromatic ammonia-lyases and aminomutases which show high structural and sequence similarities, and 
have a common electrophilic prosthetic group, the autocatalytically forming 3,5-dihydro-5-methylidene- $4 \mathrm{H}$-imidazol-4-one (MIO). ${ }^{8,9,10-12}$

Recent advances in the improvement of the functional properties of the MIO-enzymes initiated their application as biocatalysts for the synthesis of non-natural amino acids, well exemplified by the phenylalanine ammonia-lyase (PAL)-based process, developed by DSM (Netherlands), for the multiton scale production of (S)-2,3-dihydro- $1 H$-indole-2-carboxylic acid. $^{13}$

Due to its broad substrate tolerance, phenylalanine ammonia-lyase from Petroselinum crispum (PcPAL) was one of the most frequently used aromatic amino acid ammonia-lyases applied as biocatalyst. ${ }^{14-16}$ Immobilization of isolated PcPAL led to increased operational stability and enabled the employment of PcPAL for the synthesis of non-natural substrates in continuous-flow packed-bed reactors, ${ }^{17}$ and in magnetic nanoparticle-filled microfluidic systems, ${ }^{18,19}$ and provided new perspectives in the development of stable and efficient catalysts for industrial applications.

Numerous lines of evidence suggest that interactions between the amino group of the substrate L-Phe and the electrophilic MIO of PAL facilitate the ammonia-lyase reaction. ${ }^{20}$ The crystal structures of phenylalanine 2,3-aminomutases from Pantoea agglomerans (PaPAM) complexed with L-phenylalanine ${ }^{21}$ and from Taxus chinensis (TchPAM) complexed with $\mathrm{L}^{-} \alpha, \alpha$-difluoro- $\beta$-phenylalanine, ${ }^{22}$ and the tyrosine 2,3-aminomutase from Streptomyces globisporus (SgTAM) cocrystallized with L- $\alpha, \alpha$-difluoro- $\beta$-tyrosine, ${ }^{23}$ all with a covalent bond between the amino group of the substrate/inhibitor and the exocyclic methylene carbon of the MIO, supported a reaction mechanism proceeding through the so called $\mathrm{N}$-MIO intermediate. This is also in agreement with QM/MM calculations on $\mathrm{TAL}^{24}$ and $\mathrm{PAL}^{19}$ supporting ammonia elimination via an $\mathrm{N}$-MIO intermediate and suggesting the formation of similar $N$-MIO complexes as a common feature of the mechanisms for all MIO-enzymes. ${ }^{20}$
Proceeding from the $N$-MIO intermediate of PAL with the aid of the catalytically essential Tyr $110,{ }^{25}$ the elimination is either stepwise (i) through a benzylic carbanion (E1cB) or (ii) through a carbocation (E1) or (iii) it is a concerted process (E2). A thorough kinetic analysis of the PAL reaction, ${ }^{26}$ based on kinetic isotope effects of $\left[{ }^{15} \mathrm{~N}\right]$ - and/or $\left[3-{ }^{2} \mathrm{H}_{2}\right]$-phenylalanine, favored the mechanism via a carbanionic intermediate $(\mathrm{E} 1 \mathrm{cB})$. In a recent study, ${ }^{27}$ a previously unrevealed, competing MIO-independent reaction pathway was reported with PALs from Anabaena variabilis (AvPAL), Rhodotorula glutinis (RgPAL), and parsley (PcPAL) which proceeds in a non-stereoselective manner and results in the generation of both $\mathrm{L}^{-}$and D-phenylalanine derivatives. Isotope-labeling studies and mutagenesis of key active site residues were consistent with amino acid deamination occurring by a stepwise E1cB elimination mechanism in this case as well.

It was already shown that phenylalanine 2,3-aminomutase from Taxus canadensis (TcaPAM) could transform $(S)$ $\alpha$-styrylalanine (L-1a) into $(2 E, 4 E)$-5-phenylpenta-2,4-dienoic acid (2a) as the major product. ${ }^{28}$ Considering the high structural and sequence similarities between TcaPAM and PcPAL, it seemed commendable to explore the potential of PcPAL in the kinetic resolution of $\alpha$-styrylalanines and stereoselective amination of $(2 E, 4 E)$-styrylacrylates in the reverse reaction (Scheme 1).

The present study - with the aim of extending the substrate scope of PcPAL towards sterically demanding phenylalanine analogues - created mutant variants of recombinant PcPAL with an enlarged aromatic binding pocket enabling smooth fit of styrylalanines with increased distance between the aromatic moiety and the $\alpha$-stereogenic carbon into the active site.

The results of this study were rationalized by molecular modeling in the framework of a straightforward physics-based approach based on ligand/N-MIO intermediate poses/conformation sets and several molecular descriptors to approximate changes on the potential energy surface and thus characterize certain phenomena of the catalysis.
A<smiles>N[C@@H](C/C=C/c1ccccc1)C(=O)O</smiles>
rac-1a-d

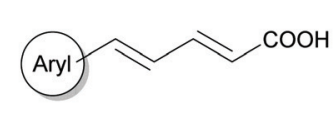

B

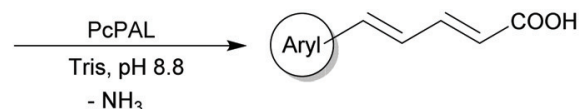

2a-d

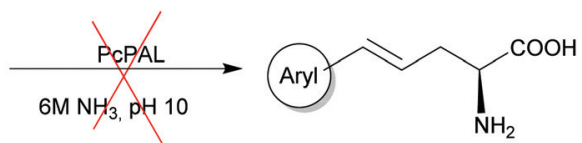

L-1a-d

Aryl:

Scheme 1 (A) Ammonia elimination from racemic styrylalanines $1 a-d$ and (B) attempted ammonia addition onto styrylacrylates $2 a-d$ catalyzed by wt- and mutant PCPALs. 


\section{Results and discussion}

\section{Initial studies and F137X-PcPAL mutant set construction}

First, to assess the applicability of wt-PcPAL to the styrylalanine compound family, the commercially available L-styrylalanine $(\mathrm{L}-\mathbf{1} \mathbf{a})$ was tested as the substrate in the ammonia elimination reaction (Scheme 1), monitored by HPLC and UV-based assays. The ${ }^{1} \mathrm{H}-\mathrm{NMR}$ spectra of the reaction mixtures confirmed the formation of (2E,4E)-5-phenylpenta-2,4-dienoic acid (2a) as the product. Kinetic studies of the ammonia elimination catalyzed by wt-PcPAL showed 14.7fold lower $k_{\text {cat }}$ and 777 -fold lower $k_{\text {cat }} / K_{\mathrm{M}}$ values for the deamination of $\mathrm{L}-\mathbf{1 a}$ in comparison with the deamination of the natural substrate, L-Phe (Table 1).

The low enzyme activity, observed with L-styrylalanine (L-1a), was rationalized by molecular modeling. Evaluation of energetics indicated as the most disadvantageous interaction the one between the phenyl ring of the $N$-MIO intermediate from $\mathrm{L}-\mathbf{1 a}$ and the phenyl ring of the residue F137 in the aromatic binding pocket of wt-PcPAL (Fig. 1). Moreover, enumeration of the possible conformations indicated three major species. In panel A of Fig. 1, two apparently catalytically active conformations, resembling the active arrangement of phenylalanine in PcPAL, ${ }^{19}$ are depicted. These two $N$-MIO intermediate conformations can result in two different arrangements of the diene product (2a), the s-cis [referred to as pro-s-cis $(p \mathrm{sc})$ ] or the s-trans [referred to as pro-s-trans $(p s t)]$ conformations. Panel B of Fig. 1 depicts a third conformation adopting a somewhat different arrangement with significantly less stress exerted by F137. However, this specimen would lead to $(2 Z, 4 E)$ 5-phenylpenta-2,4-dienoic acid which was not detected by NMR in the reaction mixture. Thus, conformation $\mathrm{L}-\mathbf{1} \mathbf{a}_{\mathrm{u}}$ could be considered an unproductive state. These modeling results implied that the reaction rate might be improved by reducing the clash between the aromatic moieties of L-1a in its $N$-MIO state and F137 within the active site of wt-PcPAL, and simultaneously by relocating the population of the unproductive conformation. It is notable that, earlier, in the case of 4-substituted cinnamates as substrates in the reverse amination reaction with PcPAL, mutations of the F137 site were efficacious. ${ }^{29}$ Therefore, to provide more space for the phenyl ring of $\mathrm{L}-\mathbf{1 a}$, the residue Phe137 in the hydrophobic pocket of wt-PcPAL was changed to smaller hydrophobic residues Val, Ala, and Gly in mutants F137V-, F137A-, and F137G-PcPAL, respectively. The

Table 1 Kinetic parameters for wt-PCPAL and F137X-PCPAL mutants in ammonia elimination from L-phenylalanine and L-styrylalanine (L-1a)

\begin{tabular}{|c|c|c|c|c|c|c|}
\hline \multirow[b]{2}{*}{ PcPAL } & \multirow[b]{2}{*}{$K_{\mathrm{M}}(\mu \mathrm{M})$} & \multicolumn{2}{|c|}{ L-Phenylalanine } & \multicolumn{3}{|c|}{ L-Styrylalanine } \\
\hline & & $k_{\text {cat }}\left(\mathrm{s}^{-1}\right)$ & $k_{\text {cat }} / K_{\mathrm{M}}\left(\mathrm{M}^{-1} \mathrm{~s}^{-1}\right)$ & $K_{\mathrm{M}}(\mu \mathrm{M})$ & $k_{\text {cat }}\left(\mathrm{s}^{-1}\right)$ & $k_{\text {cat }} / K_{\mathrm{M}}\left(\mathrm{M}^{-1} \mathrm{~s}^{-1}\right)$ \\
\hline wt & $83 \pm 5$ & $0.694 \pm 0.020$ & $8361 \pm 291$ & $4384 \pm 158$ & $0.0471 \pm 0.0003$ & $10.7 \pm 0.4$ \\
\hline F137V & $86 \pm 10$ & $0.173 \pm 0.001$ & $2011 \pm 131$ & $186 \pm 6$ & $0.4220 \pm 0.0280$ & $2269 \pm 168$ \\
\hline F137A & $1732 \pm 15$ & $0.283 \pm 0.001$ & $163 \pm 2$ & $1173 \pm 70$ & $0.1320 \pm 0.0026$ & $112.5 \pm 7.2$ \\
\hline F137G & $4969 \pm 153$ & $0.052 \pm 0.003$ & $10.4 \pm 0.9$ & $4120 \pm 270$ & $0.0345 \pm 0.0038$ & $8.3 \pm 0.2$ \\
\hline
\end{tabular}

A

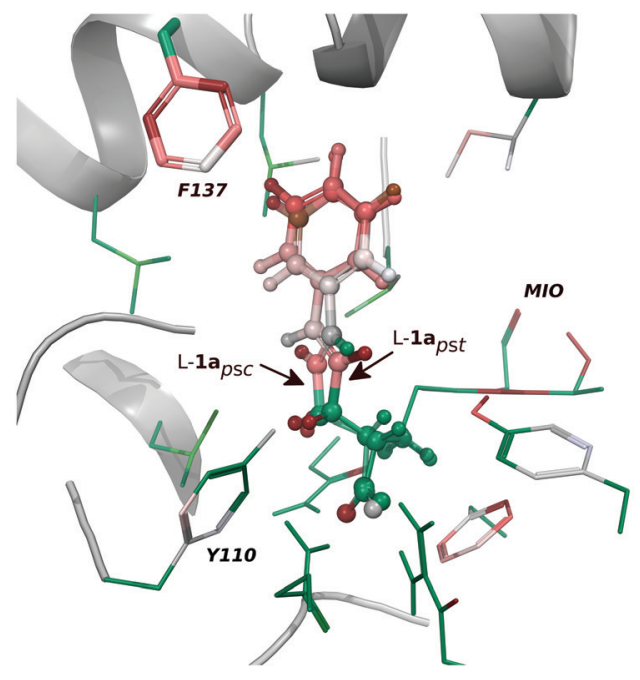

B

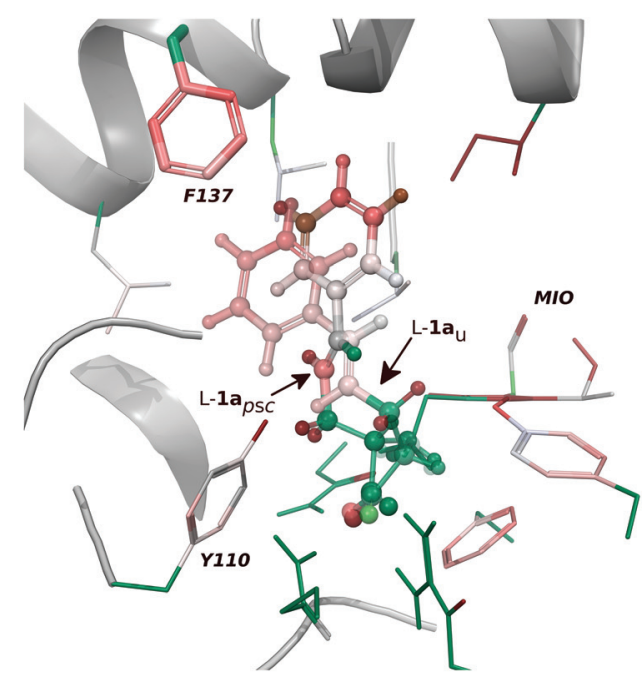

Fig. 1 Active site models of the three major conformations of the N-MIO complex of L-1a with wt-PcPAL [colors refer to the atomic contributions to the total energy ranging from green (beneficial, $\leq-5 \mathrm{kcal} \mathrm{mol}^{-1}$ ) to red (detrimental, $\geq 2 \mathrm{kcal} \mathrm{mol}^{-1}$ )]. (A) The two presumably catalytically active conformations $\mathrm{L}-1 \mathrm{a}_{p s c}$ and $\mathrm{L}-1 \mathrm{a}_{\text {pst }}$ leading to the product $2 \mathrm{a}$ in $\mathrm{s}$-cis (synperiplanar) or s-trans (antiperiplanar) arrangements, respectively. (B) The apparently catalytically inactive conformation $\mathrm{L}-1 \mathrm{a}_{\mathrm{u}}$ compared to the apparently catalytically active $\mathrm{L}-1 \mathrm{a}_{\mathrm{psc}}$ conformation. 
kinetic parameters of the wild-type and the mutant PcPALs were determined in the ammonia elimination reaction for the natural substrate $\mathrm{L}$-Phe and for L-1a (Table 1).

The ratio of $k_{\text {cat }}$ and $K_{\mathrm{M}}$ - often referred to as the "catalytic efficiency" - is a useful index for comparing the efficiency of an enzyme acting on alternative substrates. ${ }^{30}$ Not surprisingly, all mutants showed decreased - declining with side chain volume - catalytic efficiencies in the ammonia elimination reaction of the natural substrate, L-Phe, in comparison with wtPcPAL. However, it can be clearly seen that F137V has superior catalytic efficiency with L-1a as substrate, with nearly 240 -fold increased $k_{\text {cat }} / K_{\mathrm{M}}$ value compared to wt-PcPAL. The F137A mutation also provided an increased $k_{\text {cat }} / K_{\mathrm{M}}$ value with L-1a (10.5-fold enhancement), while the F137G mutation showed no beneficial effect on the transformation of L-1a. Interestingly, $k_{\text {cat }}$ values showed also substantial variances. The trends and maxima were almost the same as those in the case of the $k_{\text {cat }} / K_{\mathrm{M}}$ values. Regarding L-Phe, $k_{\text {cat }}$ declined with decreasing side chain volume, except for a surprising spike with F137A-PcPAL. Similarly, F137V-PcPAL with L-1a showed a tremendous, almost 9-fold increase; F137A showed only a moderate 2.8-fold increase; and F137G showed no improvement in $k_{\text {cat }}$ compared to wt-PcPAL.

A comparison of the covalent pro-s-cis intermediates from L-1a within wt-PcPAL and F137V-PcPAL is shown in panel $\mathbf{A}$ of Fig. 2. The aromatic moiety of the $N$-MIO intermediate from L-1a is forced towards I460 within the active site of wt-PcPAL, unlike in the case of the more relaxed complex within F137V-PcPAL; meanwhile, the alanyl substructure of the substrate - which is directly involved in bond rearrangement - is kept relatively unchanged in both cases. It is worth noting that upon the binding of L-1a to wt-PcPAL the active site supposedly undergoes a conformational change at the I460-side chain which reshapes the active site and alters the energetics of distinct substrate conformations.

\section{Synthetic applications in kinetic resolution}

Next, we wanted to explore the potential of F137V-PcPAL in the synthetically valuable ammonia elimination and addition reactions of various styrylalanines and their acrylic counterparts. Therefore, racemic styrylalanines rac-1a-d as well as the corresponding styrylacrylates $\mathbf{2 a - d}$ were synthesized (see Schemes S1 and S2 in the ESI $\dagger$ ) and tested with F137V-PcPAL and wt-PcPAL as biocatalysts (Scheme 1).

In the ammonia elimination reaction all styrylalanines (rac1a-d) were accepted as substrates by wt-PcPAL as well as by F137V-PcPAL. However, the F137V mutant showed significantly improved catalytic activities $\left(k_{\text {cat }}\right.$ and $\left.k_{\text {cat }} / K_{\mathrm{M}}\right)$ in comparison with the wild-type enzyme in all cases (Table 2).

The synthetic usefulness of F137V-PcPAL towards styrylalanines in the ammonia elimination reactions was further tested by kinetic resolutions (KRs) with $0.1 \mathrm{mmol}$ rac-1a-d at $5 \mathrm{mM}$ concentration using $0.5-1.0 \mathrm{mg}$ of pure PcPALs. The conversion of the PcPAL-catalyzed reactions from racemic styryl-
A

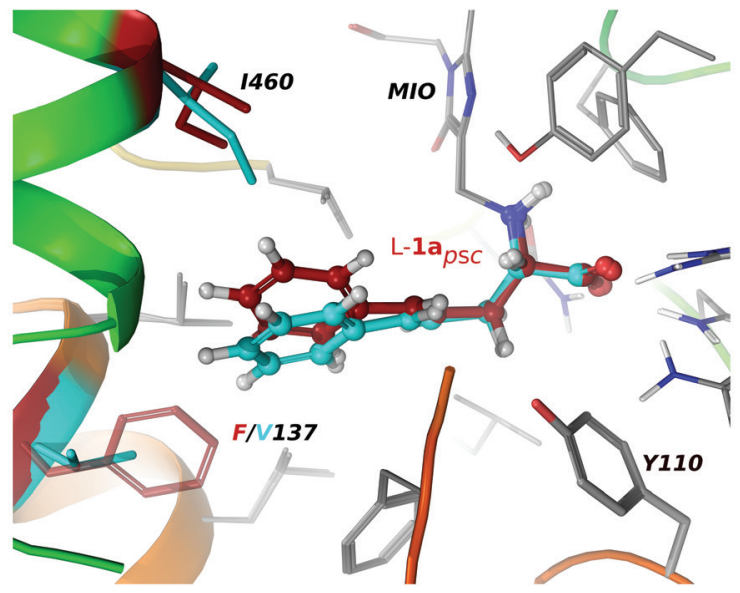

B

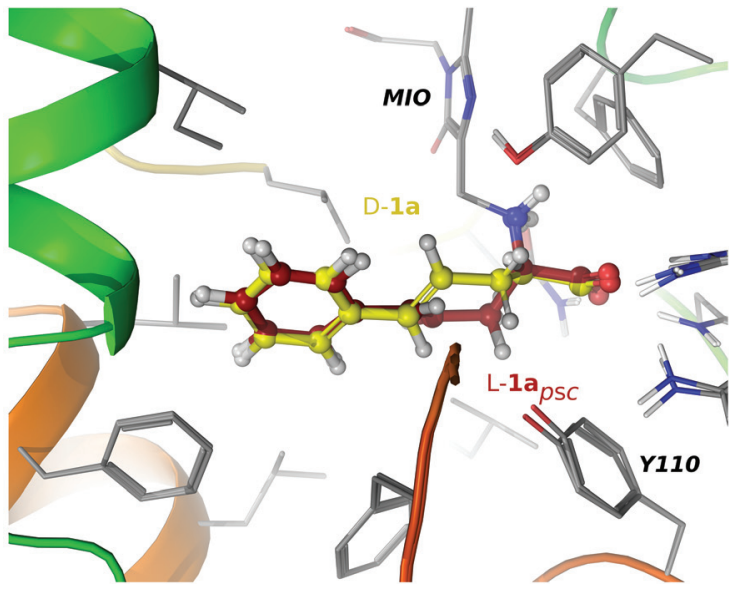

Fig. 2 Molecular models of various N-MIO intermediates in PcPALs. (A) Arrangement of the covalent intermediate L-1a $a_{p s c}$ in wt-PcPAL (relevant residues are in red) and F137V-PcPAL (relevant residues are in cyan). Note the different side chain conformations of 1460 . (B) Arrangement of the

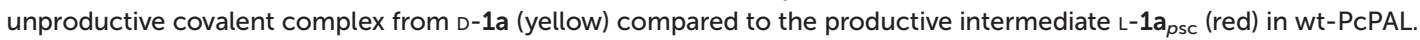

Table 2 Kinetic parameters for wt- and F137V-PcPALs in the ammonia elimination of racemic styrylalanines rac-1a-d

\begin{tabular}{|c|c|c|c|c|c|c|}
\hline Substrate & \multicolumn{3}{|l|}{ wt-PcPAL } & \multicolumn{3}{|c|}{ F137V-PcPAL } \\
\hline$r a c-\mathbf{1 a}$ & $395 \pm 6$ & $0.00620 \pm 0.00070$ & $15.6 \pm 0.9$ & $201 \pm 12$ & $0.2760 \pm 0.0130$ & $1373 \pm 97$ \\
\hline rac-1c & $28 \pm 1$ & $0.00034 \pm 0.00002$ & $12.1 \pm 0.6$ & $94.7 \pm 2$ & $0.1570 \pm 0.0020$ & $1657 \pm 10$ \\
\hline$r a c-\mathbf{1 d}$ & $287 \pm 3$ & $0.00320 \pm 0.00030$ & $11.1 \pm 0.5$ & $326 \pm 10$ & $0.0099 \pm 0.0001$ & $30.2 \pm 1.9$ \\
\hline
\end{tabular}




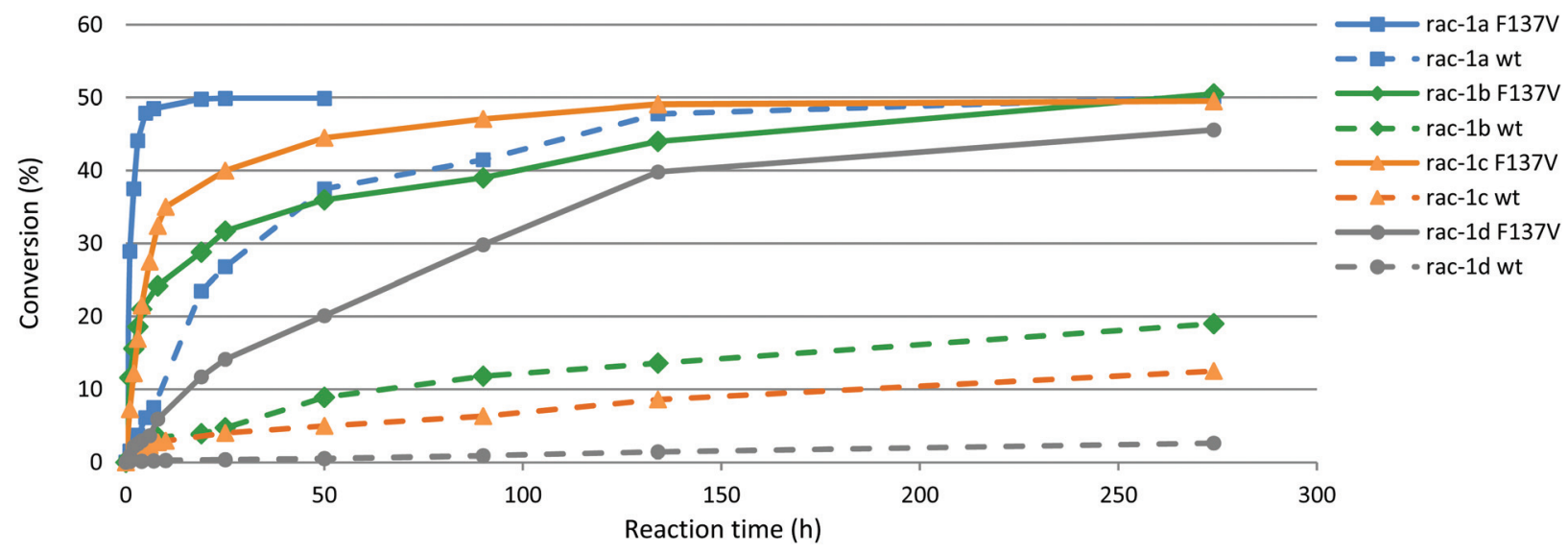

Fig. 3 Comparison of the time profiles of the conversions in the ammonia elimination reactions from rac-1a-d catalyzed by F137V-PcPAL (continuous lines) and wt-PCPAL (dashed lines).

alanines rac-1a-d (Fig. 3), and the enantiomeric excess of the residual substrates D-1a-d were both monitored (Table 3). In the case of longer reaction times $(>48 \mathrm{~h})$, a fresh enzyme batch was added to the reaction mixture at the end of each $48 \mathrm{~h}$ period to overcome enzyme inactivation during long incubation times.

Time course analysis of the conversion of the KRs of rac-1a-d (Fig. 3) also indicated the beneficial catalytic properties of F137V-PcPAL compared to that of wt-PcPAL. The theoretically possible conversion in a kinetic resolution (KR) with exclusive selectivity (50\%) could be almost perfectly approached (c $>49 \%$ ) with the F137V mutant in reactions of rac-1a,c after moderate reaction times ( $24 \mathrm{~h}$ and $134 \mathrm{~h}$, respectively) and in the case of $r a c-\mathbf{1 b}, \mathbf{d}$ after longer incubation times $(274 \mathrm{~h}$ and $300 \mathrm{~h}$, respectively). The unusually long time required for the compounds rac-1b,d can be significantly shortened by using higher enzyme to substrate ratios. This might be easily performed by applying immobilized forms of PcPAL in microreactors. ${ }^{17}$

On the other hand, in reactions of racemic styrylalanines rac-1a-d with wt-PcPAL, almost complete conversion of the L-enantiomer could be obtained only with rac-1a $(c>49 \%$ after

Table 3 Kinetic resolution of styrylalanines $r a c-1 a-d$ and enantiomeric excess of the residual $\mathrm{D}-1 \mathrm{a}-\mathrm{d}$ in the ammonia elimination reactions catalyzed by PCPAL variants

\begin{tabular}{lllllll}
\hline Entry & PcPAL & Substrate & $\begin{array}{l}\text { Time } \\
(\mathrm{h})\end{array}$ & $c(\%)$ & $\begin{array}{l}\mathrm{ee}_{\text {theor }}{ }^{a} \\
(\%)\end{array}$ & $\begin{array}{l}\mathrm{ee}_{\text {obs }} \\
(\%)\end{array}$ \\
\hline 1 & F137V & rac-1a & 24 & 50 & 100 & $>99$ \\
2 & & rac-1b & 274 & 50 & 100 & $>99$ \\
3 & & rac-1c & 134 & 50 & 100 & $>99$ \\
4 & & rac-1d & 300 & 50 & 100 & $>99$ \\
5 & Wild-type & rac-1a & 274 & 50 & 100 & $>98$ \\
6 & & rac-1b & 504 & 29 & 41 & 41 \\
7 & & rac-1c & 600 & 36 & 56 & 55 \\
8 & & rac-1d & 600 & 31 & 45 & 41
\end{tabular}

${ }^{a} e_{\text {theor }}=c /(1-c)$ for a fully selective kinetic resolution.
$274 \mathrm{~h}$ ), while the conversions of rac-1b-d could not approach the theoretically possible value within 500-600 $\mathrm{h}$.

KRs of rac-1a-c with wt-PcPAL showed that enantiomeric excess of residual D-1a-c fractions were in close agreement with the theoretical values of a fully selective KR indicating excellent enantiomer selectivity and preference of the process to digest the L-enantiomers, L-1a-c (Table 3). Although the enantiomeric excess of the residual $\mathrm{D}$-1d fractions was somewhat smaller than that expected for a fully selective KR, it was not possible to determine whether this was due to experimental errors of the HPLC process or due to the non-perfect enantiomer selectivity of the KR from rac-1d.

KRs of rac-1a-d with F137V-PcPAL, however, showed that the residual $\mathrm{D}-\mathbf{1 a}-\mathbf{d}$ fractions had enantiomeric excess values over $99 \%$ indicating unquestionably exclusive enantiomer selectivity in all cases. This was also obvious from the time course curves of conversions approaching asymptotically the $50 \%$ value when F137V-PcPAL was applied as the biocatalyst in the KRs (Fig. 3). Time course profiles of the reactions and the comparison of the kinetic constants with L-1a (Table 1) and with rac-1a (Table 2) suggest that D-styrylalanine inhibits the ammonia elimination of L-1a with both wt-PcPAL and F137V-PcPAL. If D-1a had no interaction with wt-PcPAL, then only a 2-fold higher apparent $K_{\mathrm{M}}$ of the racemate rac-1a would be observed as compared to the pure L-enantiomer L-1a without affecting the $k_{\text {cat }}$ value. However, when rac-1a was applied as the substrate instead of the pure L-enantiomer L-1a, the $V_{\max }$ (thus implicitly the apparent $k_{\text {cat }}$ value) decreased 7.6fold, while the $K_{\mathrm{M}}$ value decreased 11 -fold. With F137V-PcPAL, the differences became less significant, $k_{\text {cat }}$ decreased only 1.5fold, and $K_{\mathrm{M}}$ showed only a minor variation, within the range of experimental errors. Because the residual fractions from the KRs of rac-1a-d had quite high enantiomeric excess at $50 \%$ conversion (ee $>99 \%$, see Table 3), the D-enantiomers D-1a-d were apparently not converted. This implied that $\mathrm{D}-\mathbf{1 a}$ is a reversible inhibitor with considerable affinity forming an unproductive enzyme-D-substrate complex. The covalent, unproductive $N$-MIO complex from D-1a showed astonishing 
overlap with the productive intermediate $\mathrm{L}-\mathbf{1} \mathbf{a}_{p s t}$ within the active site of wt-PcPAL (panel B in Fig. 2).

\section{Rationalization of the reactions of styrylalanines rac-1a-d catalyzed by the PcPAL variants}

To obtain a more detailed view of the catalytic process, a quantitative model was created and validated. Because $N$-MIO complexes were assumed to be a common feature of the mechanism for all MIO-enzymes, ${ }^{20}$ the enzyme-substrate complexes within the active site of the PcPAL variants were constructed as $N$-MIO intermediates of $\mathrm{L}^{-}$and $\mathrm{D}-\mathbf{1 a}-\mathbf{d}$ applying an induced-fit covalent docking protocol which was previously used to rationalize the reactions of various substrates within another MIO enzyme, the phenylalanine 2,3-aminomutase from Pantoea agglomerans. ${ }^{31}$

The non-covalent substrate-binding states of $\mathrm{L}^{-}$and $\mathrm{D}-\mathbf{1 a}-\mathbf{d}$ directly preceding their $\mathrm{N}$-MIO intermediate states - were also modeled. Because the calculations did not reveal any unproductive states for these non-covalent complexes, they will not be discussed hereafter.

The occurrence of the non-stereoselective, MIO-independent reaction pathway ${ }^{27}$ was ruled out experimentally. The attempted ammonia elimination from rac-1a-d by wt-PcPAL with the inactivated MIO group (obtained by treatment with sodium borohydride) ${ }^{32}$ showed no product formation. The conversion of 4-nitrophenylalanine with the sodium borohydride treated wt-PcPAL served as a positive control for the integrity of the residual parts of the active site.

To investigate the catalytic activities quantitatively with all substrate and enzyme mutant combinations, the apparent $k_{\text {cat }}$ values - as determined from the maximum reaction rates according to the left-hand side of eqn (1) - were decomposed into their constituents.

At substrate saturation, when the concentration of the free enzyme is negligible, four species of enzyme-substrate intermediate complexes $\left(E_{\mathrm{L}-p s c}, E_{\mathrm{L}-p s c}, E_{\mathrm{L}-\mathrm{u}}\right.$, and $\left.E_{\mathrm{D}}\right)$ can be present in thermal equilibrium (allosteric inhibition was not considered in this study). As discussed previously, from the L-enantiomer two catalytically active enzyme-substrate intermediate complexes (the s-cis and s-trans L-1a-d-N-MIO states, abbreviated as $\left.E_{\mathrm{L}-p s c}, E_{\mathrm{L}-p s t}\right)$ and an unproductive one (the unproductive L-1a-d-N-MIO states, abbreviated as $E_{\mathrm{L}-\mathrm{u}}$ ) could be formed, while another unproductive complex could be formed from the D-enantiomers (the unproductive D-1a-d-N-MIO states, abbreviated as $E_{\mathrm{D}}$ ). Thus, according to eqn (1), the catalytic activity is the sum of the activities of $E_{\mathrm{L}-p s c}$ and $E_{\mathrm{L}-p s t}$.

$$
V_{\max }=k_{\mathrm{cat}}\left[E^{*}\right]=k_{\mathrm{cat}, \mathrm{L}-p \mathrm{sc}}\left[E_{p \mathrm{sc}}\right]+k_{\mathrm{cat}, \mathrm{L}-p \mathrm{st}}\left[E_{p s t}\right]
$$

Expressing the substrate concentrations as molar fractions and substituting the Eyring equation yields eqn (2):

$$
k_{\text {cat }}=\frac{k_{\mathrm{B}} T}{h} \mathrm{e}^{\Delta G_{\mathrm{L}-p s c}^{\#} / R T} x_{p s c}+\frac{k_{\mathrm{B}} T}{h} \mathrm{e}^{\Delta G_{\mathrm{L}-p s t}^{\#} / R T} x_{p s t}
$$

where $T$ is the temperature, $k_{\mathrm{B}}$ is the Boltzmann constant, $h$ is the Planck constant, $\Delta G^{\#}$ is the corresponding Gibbs energy of activation, and $x$ is the corresponding molar fraction. To approximate the Gibbs energy of activation, two descriptors were used: one was associated with the acidity of the $\beta$-proton ${ }_{\mathrm{cB}}{ }^{R} \Delta E$, Table 4$)$, and the other one was associated with the steric strain ( ${ }_{\text {ster }}^{R} \Delta E$, Table 4). Applying these descriptors, eqn (3) is derived:

$$
k_{\text {cat }}=a\left(\mathrm{e}^{b^{*} \Delta E_{\mathrm{L}-p s c}^{\#} / R T+\ln x_{\mathrm{L}-p s c}}+\mathrm{e}^{b^{*} \Delta E_{\mathrm{L}-p s t}^{\#} / R T+\ln x_{\mathrm{L}-p s t}}\right)
$$

where $a$ and $b$ are constants, and $\Delta E^{\#}$ is the sum of $\operatorname{strain}^{R} \Delta E$ and ${ }_{\mathrm{cB}}^{R} \Delta E$.

Non-linear estimation of the constants in eqn (3) gave statistically significant regression $\left(R^{2}=0.8, p=0.002\right)$ and parameters $(a=90.63, p=0.023 ; b=0.0791, p=0.014)$. The complete derivation of eqn (3) is described in the ESI. $\dagger$

Evaluation of the F137V mutation based on computed data (Table 4) clearly demonstrated that the affinities of $\mathrm{L}-\mathbf{1 a}-\mathbf{d}$ in the pro-s-cis conformation $\left({ }_{\mathrm{b}}{ }^{R} \Delta E_{\mathrm{L}-p \mathrm{~s} c}\right)$ increased substantially, as was assumed. Moreover, the affinities of $\mathrm{L}-\mathbf{1 a}-\mathbf{d}$ in the pro-strans conformation increased even more, as their population

Table 4 Calculated relative binding energies $\left({ }_{b}{ }^{R} \Delta E\right)$, rounded values of molar fractions of the various covalent $N$-MIO complexes $(x)$, energy-based descriptors of the acidity of their pro-S $\beta$-hydrogen $\left({ }_{C B}{ }^{R} \Delta E\right)$ and steric strain of activation (strain ${ }^{R} \Delta E$ ) for intermediates of compound $1 \mathrm{a}-\mathrm{d}$ in PcPAL

\begin{tabular}{|c|c|c|c|c|c|c|c|c|c|c|c|}
\hline PcPAL & Substrate & $\begin{array}{l}{ }^{R} \Delta E_{\mathrm{L}-p \mathrm{sc}}{ }^{b} \\
\left(\mathrm{kcal} \mathrm{mol}^{-1}\right)\end{array}$ & $\begin{array}{l}x_{\mathrm{L}-p s c}{ }^{c} \\
(\%)\end{array}$ & $\begin{array}{l}x_{\mathrm{L}-p s t}{ }^{c} \\
(\%)\end{array}$ & $\begin{array}{l}x_{\mathrm{D}}{ }^{c} \\
(\%)\end{array}$ & $\begin{array}{l}x_{\mathrm{L}-\mathrm{u}}{ }^{c} \\
(\%)\end{array}$ & $\begin{array}{l}{ }^{R}{ }^{R} \Delta E_{\mathrm{L}-p \mathrm{~s} c}{ }^{b} \\
\left(\text { kcain }^{\mathrm{mol}} \mathrm{mol}^{-1}\right)\end{array}$ & $\begin{array}{l}{ }^{R} \Delta E_{\mathrm{L}-p s}{ }^{b} \\
\left(\mathrm{krcal}^{\mathrm{s}} \mathrm{mol}^{-1}\right)\end{array}$ & $\begin{array}{l}{ }_{\mathrm{cB}}^{R} \Delta E_{\mathrm{L}-p s c}{ }^{b} \\
\left(\mathrm{kcal} \mathrm{mol}^{-1}\right)\end{array}$ & $\begin{array}{l}{ }_{\mathrm{cB}}^{R} \Delta E_{\mathrm{L}-p s t}{ }^{b} \\
\left(\mathrm{kcal} \mathrm{mol}^{-1}\right)\end{array}$ & $\begin{array}{l}{ }_{\mathrm{cB}}^{R} \Delta E_{\mathrm{L}-p s t}-\mathrm{cB}^{R} \Delta E_{\mathrm{L}-p \mathrm{~s} c}{ }^{b} \\
(\mathrm{kcal} \mathrm{mol} \\
\end{array}$ \\
\hline \multirow[t]{4}{*}{ Wild-type } & $1 a$ & 13.0 & 99.7 & 0.2 & 0.1 & 0.0 & 11.0 & 16.2 & -2.2 & 3.8 & 6.1 \\
\hline & $1 b$ & 22.5 & 2.1 & 0.0 & 0.0 & 97.9 & 22.5 & 28.5 & -1.5 & -1.8 & -0.3 \\
\hline & $1 c^{a}$ & 13.6 & 41.5 & 0.0 & 0.7 & 57.8 & 12.9 & 20.4 & 11.9 & 8.2 & -3.6 \\
\hline & $1 d$ & 33.7 & 93.4 & 0.0 & 0.0 & 6.6 & 33.9 & 42.4 & -11.4 & -11.5 & 0.1 \\
\hline \multirow[t]{4}{*}{ F137V } & $1 a$ & -3.3 & 95.2 & 4.8 & 0.0 & 0.0 & -0.7 & 1.1 & -4.6 & -10.7 & -6.2 \\
\hline & $1 b$ & -3.2 & 99.9 & 0.1 & 0.0 & 0.0 & 1.4 & 5.7 & -5.4 & -7.7 & -2.4 \\
\hline & $1 c^{a}$ & 1.4 & 60.9 & 5.0 & 0.8 & 0.0 & 5.3 & 6.8 & 11.3 & 0.5 & -10.8 \\
\hline & $1 d^{a}$ & 22.7 & 0.3 & 18.1 & 0.9 & 80.7 & 25.3 & 22.9 & -31.6 & -20.4 & 11.3 \\
\hline
\end{tabular}
variants. The subscript letters $L$ and $\mathrm{D}$ correspond to the actual enantiomer; psc, pst, and $\mathrm{u}$ correspond to the $\mathrm{s}$-cis, $\mathrm{s}$-trans product forming and the unproductive $1 \mathrm{a}-\mathrm{d}-\mathrm{N}-\mathrm{MIO}$ states

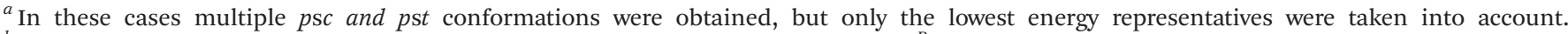

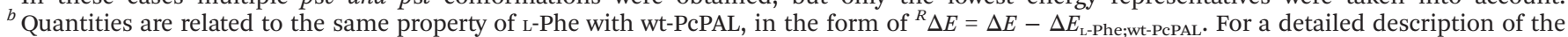

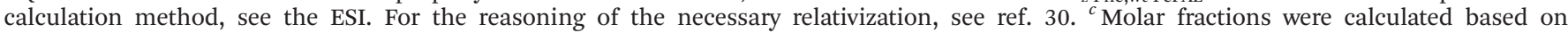
Boltzmann probabilities incorporating all substrate conformations. 
increased relative to the pro-s-cis conformation $\left(x_{\mathrm{L}-p s t} v s . x_{\mathrm{L}-p s c}\right)$, with the exception of L-1d with F137V-PcPAL. The unproductive complexes of 1a-d $\left(x_{\mathrm{D}}\right.$ and $\left.x_{\mathrm{L}-\mathrm{u}}\right)$, however, showed a more complex situation. By the F137V-mutation, in some cases unproductive states were displaced (e.g. 1c), and in some other cases they were introduced (e.g. 1d). These results indicated that a simple increase of the active site volume is not sufficient from the standpoint of enzyme design, and a more sophisticated active site shape altering scheme - taking the relative spatial requirements of the intermediate states and unproductive states into account - should be employed. Inspection of the descriptors for the acidity of the pro-S $\beta$-hydrogen $\left({ }_{\mathrm{cB}}{ }^{R} \Delta E\right)$ which was derived from single point DFT calculations on a truncated part of the intermediate model - revealed that in almost all cases the acidity of the pro-s-trans conformations compared to the pro-s-cis conformations ${ }_{(\mathrm{cB}}{ }^{R} \Delta E_{\mathrm{L}-p s t}$ $\left.{ }_{\mathrm{cB}}^{R} \Delta E_{\mathrm{L}-p s c}\right)$ was comparable or higher, except for $\mathbf{1 b} / \mathrm{wt}-\mathrm{PcPAL}$ and 1d/F137V-PcPAL. Thus, the higher proportion of the pro-strans conformations $\left(x_{\mathrm{L}-p s t}\right)$, enabling more facilitated reaction due to the more acidic pro-S $\beta$-hydrogens, could contribute to increased activity of F137V-PcPAL. Moreover, the acidity descriptors ${ }_{\mathrm{cB}}{ }^{R} \Delta E_{\mathrm{L}-p s c}$ and ${ }_{\mathrm{cB}}^{R} \Delta E_{\mathrm{L}-p s t}$ varied remarkably in wtand F137V-PcPAL, mostly due to changes in dihedral angle between the phenyl ring and the conjugated double bond of the styryl moiety. The more planar the skeleton was, the better the dispersion of negative charge due to the higher degree of conjugation. This implied that in an efficient enzyme design protocol, the substrate affinity and electronic effects should be monitored simultaneously.

This exploratory model validates the very concept of our computations and can be used as a tool to analyze various factors of importance in catalysis and to provide valuable input for further studies. Although this model was not expected to predict the apparent $k_{\text {cat }}$ with high accuracy, it enabled us to predict the order of magnitude of the catalytic activity for several further congeneric substrates.

With our model, we examined the behavior of further substituted styrylalanines bearing bromo, cyano, fluoro, and tri- fluoromethyl substituents at position 4 (Table 5). Calculations with wt-PcPAL predicted rac-4-fluorostyrylalanine and rac-4cyanostyrylalanine to be poor substrates behaving similarly to rac-styrylalanine, rac-1a. Modeling forecast rac-4-bromo- and rac-4-trifluorostyrylalanines to be extremely poor substrates or reversible inhibitors $\left(k_{\text {cat-pred }} \leq 0.0001 \mathrm{~s}^{-1}\right)$.

The calculations predicted that the F137V mutant of PcPAL would be inefficient only in KR of rac-4-trifluorostyrylalanine $\left(k_{\text {cat-pred }} \leq 0.0001 \mathrm{~s}^{-1}\right)$. Modeling within this mutant indicated comparable high activity for $r a c$ - 4 -fluorostyrylalanine $\left(k_{\text {cat-pred }}=\right.$ $0.18 \mathrm{~s}^{-1}$ ) as for rac-styrylalanine ( $r a c-1 \mathrm{a}: k_{\text {cat }}=0.28 \mathrm{~s}^{-1}$ ). Somewhat lower catalytic activities were predicted for rac-4bromo- and rac-4-cyanostyrylalanines $\left(k_{\text {cat-pred }}=0.120 \mathrm{~s}^{-1}\right.$ and $0.098 \mathrm{~s}^{-1}$, respectively) being in the range of the activity of rac4-chlorostyrylalanine ( $r a c-1 \mathrm{c}: k_{\mathrm{cat}}=0.16 \mathrm{~s}^{-1}$ ).

\section{Study of ammonia addition onto styrylacrylates 2a-d with PcPALs}

Regrettably, no 1a-d could be detected by HPLC in the attempted ammonia addition reactions of styrylacrylates $\mathbf{2 a - d}$ with either wt-, F137V-, F137A-, or F137G-PcPAL even after 20 days (Scheme 1, for details see section 5.6 of the ESI†). The possible reasons for these results were analyzed by computer modeling in the case of wt- and F137V-PcPAL. It was not surprising that the relative binding energies of 2a-d indicated poor binding to wt-PcPAL, which was remarkably improved with F137V-PcPAL (Table $6,{ }_{\mathrm{b}}{ }^{R} \Delta E_{\text {mono }}$ ). Modeling revealed presumably unproductive ligand poses for $\mathbf{2 a - d}$ with both PcPAL variants in almost all cases with higher binding affinity as compared to the possibly reactive arrangements of $2 \mathbf{a}-\mathbf{d}$. The case of 2a within F137V-PcPAL is shown in Fig. 4. Panel A depicts the lower energy arrangement of the putatively inactive conformation of 2a with a bidentate salt bridge between R354 and the carboxylate group (in blue) compared to the putatively catalytically active conformation forming a monodentate salt bridge (in cyan).

Panel B of Fig. 4 depicts models of the possible arrangements of 2a within F137V-PcPAL with an elongated distance

Table 5 Calculated relative binding energies $\left(b^{R} \Delta E\right)$, rounded values of molar fractions of the various covalent $N$-MIO complexes $(x)$, energy-based descriptors of the acidity of their pro-S $\beta$-hydrogen $\left({ }_{C B}{ }^{R} \Delta E\right)$ and steric strain of activation $\left(\right.$ strain $\left.{ }^{R} \Delta E\right)$ for intermediates of further 4 -substituted styrylalanines in PCPAL variants, and predicted $\left(k_{\text {cat-pred }}\right)$ values for the corresponding reactions. The subscript $L$ and $D$ correspond to the actual enantiomer; psc, pst, and $\mathrm{u}$ correspond to the s-cis, s-trans product forming and the unproductive 4-substituted styrylalanine-N-MIO states

\begin{tabular}{|c|c|c|c|c|c|c|c|c|c|c|c|}
\hline PcPAL & 4-Substituent ${ }^{a}$ & $\begin{array}{l}{ }^{R} \Delta E_{\mathrm{L}-p s c}{ }^{b} \\
\left(\mathrm{kcal} \mathrm{mol}^{-1}\right)\end{array}$ & $\begin{array}{l}x_{\mathrm{L}-p s c}{ }^{c} \\
(\%)\end{array}$ & $\begin{array}{l}x_{\mathrm{L}-p s t}{ }^{c} \\
(\%)\end{array}$ & $\begin{array}{l}x_{\mathrm{D}}{ }^{c} \\
(\%)\end{array}$ & $\begin{array}{l}x_{\mathrm{L}-\mathrm{u}}{ }^{c} \\
(\%)\end{array}$ & $\begin{array}{l}{ }_{\text {Strain }}{ }^{R} \Delta E_{\mathrm{L}-p}{ }^{b}{ }^{b} \\
\left(\mathrm{kcal} \mathrm{mol}^{-1}\right)\end{array}$ & $\begin{array}{l}\operatorname{Strain}^{R} \Delta E_{\mathrm{L}-p \mathrm{ss} t}{ }^{b} \\
\left(\mathrm{kcal}^{\mathrm{mol}} \mathrm{mol}^{-1}\right)\end{array}$ & $\begin{array}{l}{ }_{\mathrm{cB}}^{R} \Delta E_{\mathrm{L}-p s c}{ }^{b} \\
\left(\mathrm{kcal} \mathrm{mol}^{-1}\right)\end{array}$ & $\begin{array}{l}{ }_{\mathrm{cB}}^{R} \Delta E_{\mathrm{L}-p s t}{ }^{b} \\
\left(\mathrm{kcal} \mathrm{mol}^{-1}\right)\end{array}$ & $\begin{array}{l}k_{\text {cat-pred }} \\
\left(\mathrm{s}^{-1}\right)\end{array}$ \\
\hline \multirow[t]{2}{*}{ Wild-type } & F- & 13.2 & 88.0 & 0.0 & 0.0 & 12.0 & 13.5 & 20.3 & -0.3 & -1.5 & 0.014 \\
\hline & NC- & 33.7 & 93.4 & 0.0 & 0.0 & 6.6 & 33.9 & 42.4 & -11.4 & -11.5 & 0.004 \\
\hline \multirow[t]{2}{*}{ F137V } & $\mathrm{F}-$ & -4.3 & 99.3 & 0.7 & 0.0 & 0.0 & 0.6 & 3.6 & -5.7 & -6.9 & 0.180 \\
\hline & $\mathrm{CF}_{3^{-}}$ & 15.5 & 0.0 & 0.0 & 0.0 & 100.0 & 21.5 & 15.5 & -6.8 & -8.2 & $<0.0001$ \\
\hline
\end{tabular}

\footnotetext{
${ }^{a}$ Substituent of the further 4-substituted styrylalanines. ${ }^{b}$ Quantities are related to the same property of L-Phe with wt-PcPAL, in the form of ${ }^{R} \Delta E=\Delta E-\Delta E_{\mathrm{L}-\mathrm{Phe} ; \mathrm{wt} \text {-PcPAL}}$. For the detailed description of the calculation method, see the ESI. For the reasoning of the necessary relativization, see ref. 30. ${ }^{c}$ Molar fractions were calculated based on Boltzmann probabilities incorporating all substrate conformations.
} 
Table 6 Calculated relative ligand binding energies $\left({ }_{\mathrm{b}}{ }^{R} \Delta E\right)$ and rounded values of molar fractions of mono- and bidentate carboxylate binding modes $(x)$ for $\mathbf{2 a}-\mathbf{d}$ [the subscript mono and bi relate to the lowest energy ligand poses that form a monodentate (putatively active pose) or bidentate (putatively inactive pose) salt bridge]

\begin{tabular}{|c|c|c|c|c|c|c|}
\hline $\begin{array}{l}\text { PcPAL } \\
\text { Compound }\end{array}$ & \multicolumn{3}{|l|}{ wt-PcPAL } & \multicolumn{3}{|l|}{ F137V-PcPAL } \\
\hline $2 \mathbf{b}$ & 25.8 & 18.0 & 81.9 & -0.2 & 77.9 & 14.4 \\
\hline $2 c$ & 20.4 & 0.1 & 75.8 & 2.0 & 0.6 & 91.3 \\
\hline $2 d$ & 41.8 & 0.0 & 92.6 & 10.4 & 6.3 & 93.3 \\
\hline
\end{tabular}

${ }^{a}$ Quantities are related to the same property of $(E)$-cinnamate with wt-PcPAL, in the form of ${ }^{R} \Delta E=\Delta E-\Delta E_{(E) \text {-cin;wt-PcPAL }}$. For the detailed description of the calculation method, see the ESI. For the reasoning of the necessary relativization, see ref. $30 .{ }^{b}$ Molar fractions were calculated based on Boltzmann probabilities incorporating all ligand poses.

A

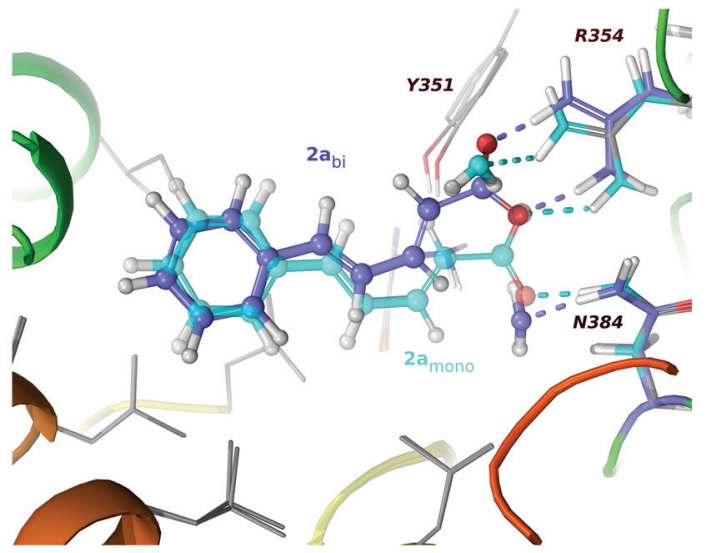

B

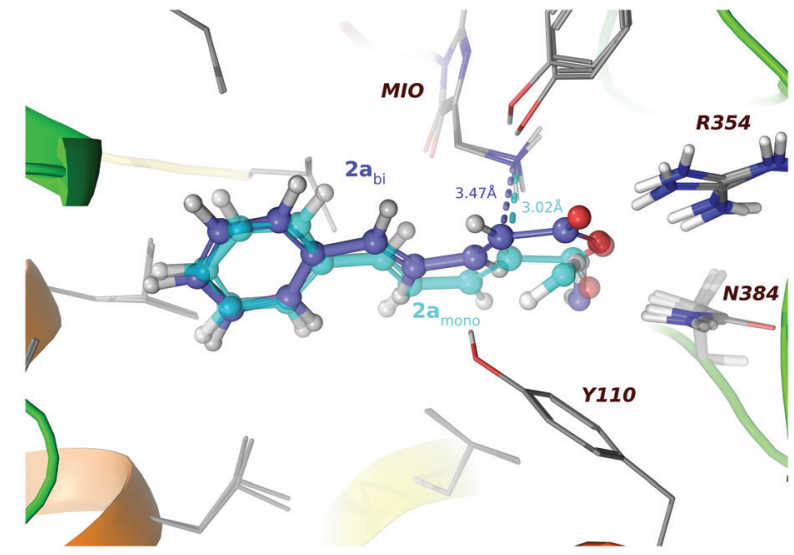

Fig. 4 Models of possible styrylacrylate 2a-arrangements within amino-enzyme $\left(\mathrm{NH}_{2}-\mathrm{N}-\mathrm{MIO}\right)$ forms of PcPAL variants. (A) Hydrogen bonds forming among the carboxylate moiety, a water molecule and R354, N384 of the bidentate and monodentate salt bridge forming poses of 2a within F137V-PcPAL. (B) The distances of the $\mathrm{N}$ atom of $\mathrm{NH}_{2}$ of the $\mathrm{NH}_{2}-\mathrm{N}-\mathrm{MIO}$ from the $\mathrm{C}_{2}$ atom of the two lowest energy mono- (2amono) or bidentate $\left(2 \mathrm{a}_{\mathrm{bi}}\right)$ carboxylate binding poses of $\mathbf{2 a}$ within F137V-PcPAL. In both panels, the model depicting $\mathbf{2} \mathbf{a}_{\text {mono }}$ (in cyan) corresponds to a product from the productive $\mathrm{N}$-MIO intermediate ( $\mathrm{L}-1 \mathrm{a}_{\mathrm{psc}}$ ), and the model depicting $2 \mathrm{a}_{\mathrm{bi}}$ (in blue) shows a low energy inactive state.

between the $\mathrm{N}$ atom of $\mathrm{NH}_{2}$ of the $\mathrm{NH}_{2}-\mathrm{N}$-MIO and the $\mathrm{C}_{2}$ atom in the model for putatively inactive conformation of $\mathbf{2 a}$ (in blue) as compared to the corresponding distance in the model including $\mathbf{2 a}$ in reactive conformation (in cyan).

Grand canonical Monte Carlo simulations indicated a water molecule for both binding poses of 2a forming a hydrogen bond with the carboxylate group of the ligand, albeit in remarkably different positions. Irrespective of the monodentate or bidentate nature of the carboxylate moiety regarding the arginine R354, the three oxygen atoms of the carboxylate group and the water always formed hydrogen bonds with residues R354 and N384 (Fig. 4, panel A). These findings agree with the experimental results found in X-ray structure of a TchPAM mutant (PDB ID: 4CQ5). ${ }^{22}$ In the structure of this enzyme homologous to PcPAL, a continuous electron density between R354 and N384 and the carboxylate of the ligand was observed in the active site complexed with $(E)$-cinnamic acid and a water which was consistent with multiple ligand poses in a similar arrangement to that found in our models for $2 \mathrm{a}$ in PcPAL.

Modeling results suggest that low binding affinities of $\mathbf{2 a - d}$ (especially to wt-PcPAL) and substrate inhibition by the in- active substrate poses of $\mathbf{2 a - d}$ in both PcPAL variants could contribute to the failure of the ammonia addition. Modeling, however, could not represent results which could completely exclude the possibility of successful ammonia addition, especially in the case of $\mathbf{2 a}, \mathbf{b}$ with F137V-PcPAL. Therefore, further reasons for the failure of ammonia addition can be proposed: (i) the thermodynamic equilibrium of ammonia addition can be too low to result in detectable amounts of L-1a-d, (ii) the low water solubility and rather poor affinity of 2a-d result in non-detectable reaction rates/product concentrations, and (iii) probably the enzyme adopts a significantly different conformation in $6 \mathrm{M}$ ammonia that makes the computational results invalid under the conditions of the ammonia addition.

\section{Experimental}

The detailed description of the materials, analytical methods, chemical synthesis of substrates rac-1a-d, 2a-d, curves from kinetic measurements, the HPLC chromatograms used for the 
Table 7 The primers used for site-directed mutagenesis

\begin{tabular}{llcc}
\hline Primer & Sequence $\left(5^{\prime}-3^{\prime}\right)$ & $T_{\mathrm{m}}^{\mathrm{pp} a}\left({ }^{\circ} \mathrm{C}\right)$ & 56 \\
\hline F137V-for & GATTAGAGTCTTGAACGCCGGAATTTTCGGAAACGGATC & $T_{\mathrm{m}}^{\mathrm{no} a}\left({ }^{\circ} \mathrm{C}\right)$ \\
F137V-rev & GGCGTTCAAGACTCTAATCAATTCCTTCTGCAAGGCTCC & 56 \\
F137A-for & GATTAGAGCCTTGAACGCCGGAATTTCGGAAACGGA & 58 & 64 \\
F137A-rev & GCGTTCAAGGCTCTAATCAATTCCTTCTGCAAGGCTCCTC & 58 & 67 \\
F137G-for & GATTAGAGGCTTGAACGCCGGAATTTCGGAAACGGA & 58 & 57 \\
F137G-rev & GCGTTCAAGCCTCTAATCAATTCCTTCTGCAAGGCTCCTC & 58 & - \\
PcPAL-for1 & CAGAACATTACTCCCTGCTTG & - & -
\end{tabular}

${ }^{a} T_{\mathrm{m}}^{\mathrm{pp}}$ and $T_{\mathrm{m}}^{\mathrm{no}}$ represent the melting temperatures for the primer-primer overlapping sequence and for the primer sequence matched with the template.

determination of conversion and enantiomeric excess values, as well as the details of the methods used for molecular modeling are given in the ESI. $\dagger$

\section{Site-directed mutagenesis}

Site-directed mutagenesis was performed using the protocol described by Naismith and Liu. ${ }^{33}$

The PCR reaction contained $10 \mathrm{ng}$ of template DNA (recombinant plasmid encoding PCPAL $^{34}$ ), a $1 \mu \mathrm{M}$ solution of primer pairs (Table 7), $200 \mu \mathrm{M}$ dNTPs and 3 units of Pfu DNA polymerase, filled to $50 \mu \mathrm{L}$ with water. The PCR cycles were initiated at $95{ }^{\circ} \mathrm{C}$ for $5 \mathrm{~min}$, followed by 15 amplification cycles. Each amplification cycle consisted of $95{ }^{\circ} \mathrm{C}$ for $1 \mathrm{~min}$, at a temperature $T_{\mathrm{m}}^{\mathrm{no}}$ of $5{ }^{\circ} \mathrm{C}$ for $1 \mathrm{~min}$ and $72{ }^{\circ} \mathrm{C}$ for $15 \mathrm{~min}$. The PCR cycles were finished with an annealing step at a $T_{\mathrm{m}}^{\mathrm{pp}}$ of $5{ }^{\circ} \mathrm{C}$ for $1 \mathrm{~min}$ and the final extension step at $72{ }^{\circ} \mathrm{C}$ for $30 \mathrm{~min}$. The PCR products were treated with 5 units of $D p n \mathrm{I}$ at $37{ }^{\circ} \mathrm{C}$ for $2 \mathrm{~h}$ and then $10 \mu \mathrm{L}$ of each PCR reaction was analyzed by agarose gel electrophoresis. An aliquot of $3 \mu \mathrm{L}$ from the above PCR product was transformed into a $100 \mu \mathrm{L}$ suspension of E. coli XL1-Blue competent cells $\left(\mathrm{OD}_{600} 2.2\right)$ by heat shock. The transformed cells were spread on a Luria-Bertani (LB) plate containing carbenicillin $\left(34 \mu \mathrm{g} \mathrm{mL} \mathrm{m}^{-1}\right)$ and chloramphenicol $\left(50 \mu \mathrm{g} \mathrm{mL}^{-1}\right)$ and incubated at $37^{\circ} \mathrm{C}$ for $16 \mathrm{~h}$. Two colonies from each plate were grown and the plasmid DNA was isolated. To verify the mutations, $400 \mathrm{ng}$ of plasmid DNA was mixed with 50 pmol of T7-for, T7-rev and PcPAL-for1, PcPALfor2 sequencing primers (Table 6) in a final volume of $15 \mu \mathrm{L}$. DNA sequencing was carried out by Genomed (Debrecen, Hungary).

\section{Protein expression}

The expression and purification of the wild-type PcPAL and the F137 V, F137A, F137G mutants were performed using the protocol described earlier. ${ }^{34}$ The protein purity and homogeneity were determined using SDS-PAGE and size-exclusion chromatography (Fig. S37 and S38†े).

\section{Enzyme activity measurements}

Enzyme assays were carried out in triplicate at $30^{\circ} \mathrm{C}$ in a $1 \mathrm{~mL}$ quartz cuvette using $0.1 \mathrm{M}$ Tris and $0.12 \mathrm{M} \mathrm{NaCl}(\mathrm{pH} 8.8)$ as a buffer at a constant concentration of wt-PcPAL or F137V-PcPAL (for details, see the ESI $\dagger$ ), varying the substrate concentration from 0.025 and $7.8 \mathrm{mM}$ until substrate saturation occurred. The kinetic measurements were based on UV-spectroscopy by monitoring the production of the acrylic derivatives $\mathbf{2 a - d}$ at wavelengths where the corresponding amino acids rac-1a-d showed no absorption (Table S1 $\dagger$ ). Kinetic constants $\left(K_{\mathrm{M}}, v_{\max }\right.$, and $k_{\text {cat }}$ ) were obtained from the Michaelis-Menten curves by non-linear fitting obtained by using MATLAB (see the ESI†).

\section{Preparative scale ammonia elimination reactions from rac-1a-d}

The enzymatic reactions were performed in $20 \mathrm{~mL}$ of Tris $(0.1 \mathrm{M}$, $0.12 \mathrm{M} \mathrm{NaCl}, \mathrm{pH}$ 8.8), containing styrylalanines (rac-1a-d, $5 \mathrm{mM}$ ) and purified PcPAL (0.5 $\mathrm{mg}$ of F137V-PcPAL or $1 \mathrm{mg}$ of wt-PcPAL). Conversion and the enantiomeric excess of the residual D-1a-d were monitored using reverse phase high performance liquid chromatography (HPLC) analysis (see the ESI $\dagger$ ). Samples $(30 \mu \mathrm{L})$ were taken from the reaction mixture after different time intervals, quenched by adding an equal volume of $\mathrm{MeOH}$, vortexed and centrifuged (13400 rpm, $12100 \mathrm{~g}, 2 \mathrm{~min})$. The supernatant was used directly for HPLC analysis after passing it through a $0.22 \mu \mathrm{m}$ nylon membrane filter. In the case of enzyme reactions over longer reaction times, another batch of enzyme was added after every $48 \mathrm{~h}$ period.

\section{Conclusions}

In this study, the substrate scope of PcPAL was extended by a small library of mutants, towards styrylalanine derivatives, a useful class of synthetically challenging phenylalanine analogues.

Although L-styrylalanine, L-1a, was accepted as the substrate by wt-PcPAL in the ammonia elimination reaction, low reaction rates were observed with the wild-type enzyme. Molecular modeling suggested that the most serious clash between the aromatic moiety of L-styrylalanine, L-1a, and the side chain of the residue $\mathrm{F} 137$ in the hydrophobic binding pocket can be 
reduced by introducing residues smaller than F137 by point mutations.

Single point mutations of F137 resulted in a small mutant library (F137X-PcPAL, X being V, A, and G), from which F137V-PcPAL showed significantly increased catalytic efficiency and could transform L-styrylalanine, L-1a, with a comparable activity to that of the wt-PcPAL with L-Phe. Furthermore, F137V-PcPAL could be used as an effective biocatalyst in the synthetically valuable kinetic resolutions by ammonia elimination from racemic styrylalanine analogues rac-1a-d providing access to D-styrylalanines $\mathrm{D}-\mathbf{1 a}-\mathbf{d}$, with highly improved catalytic efficiency compared to the wt-PcPAL in the same reactions.

The reverse ammonia addition reactions onto $(E)$-styrylacrylates 2a-d - which would be useful for the synthesis of L-styrylalanines L-1a-d - failed with either the wild-type or the mutant enzyme variants (F137 V, F137A, F137G), presumably due to the formation of energetically favorable unproductive binding states of the styrylacrylates $\mathbf{2 a - d}$.

Molecular modeling - used as an aid to explain the results of this study - revealed unusually high affinities of the D-enantiomers D-1a-d towards wt-PcPAL, but proved to be unproductive. Moreover, an unproductive and two productive conformations were revealed for the L-enantiomers L-1a-d. Thus, the proportion of the unproductive complexes acting as potent reversible inhibitors compared to the active arrangements of the L-enantiomers L-1a-d turned out to be important.

By the mutation F137V in PcPAL, the less strained arrangement of substrates L-1a-d within the active site along with the more pronounced populations of conformations with higher catalytic activities simultaneously led to the beneficial catalytic efficiency of this mutant. Modeling the behavior of further 4-substituted styrylalanines with PcPAL variants predicted the F137V mutation to be beneficial for the KRs of 4-fluoro-, 4-cyano- and 4-bromostyrylalanines, but non-effective for the KR process of 4-trifluoromethylstyrylalanine.

The results of this study open up new perspectives for the substrate scope expansion of PcPAL towards synthetically challenging phenylalanine analogues with increased length of the carbon skeleton between the aromatic moiety and the $\alpha$-stereogenic carbon.

\section{Acknowledgements}

LCB acknowledges financial support from the Romanian National Authority for Scientific Research and Innovation, CNCS-UEFISCDI (PN-II-RU-TE-2014-4-1668). LP acknowledges financial support from the Hungarian OTKA Foundation (NN-103242), the Hungarian Research and Technology Innovation Fund (KMR 12-1-2012-0140) and the New Hungary Development Plan (TÁMOP-4.2.1/B-09/1/KMR-2010-0002). The licensing of the Schrödinger Suite software package was financed by the Hungarian OTKA Foundation (K 108793).

\section{Notes and references}

1 J. A. Robinson, S. J. DeMarco, F. Gombert, K. Moehle and D. Obrecht, Drug Discovery Today, 2008, 13, 944-951.

2 N. Srinivas, P. Jetter, B. J. Ueberbacher, M. Werneburg, K. Zerbe, J. Steinmann, B. Van der Meijden, F. Bernardini, A. Lederer, R. L. A. Dias, P. E. Misson, H. Henze, J. Zumbrunn, F. O. Gombert, D. Obrecht, P. Hunziker, S. Schauer, U. Ziegler, A. Kach, L. Eberl, K. Riedel, S. J. DeMarco and J. A. Robinson, Science, 2010, 327, 10101013.

3 D. J. Craik, D. P. Fairlie, S. Liras and D. Price, Chem. Biol. Drug Des., 2013, 81, 136-147.

4 S. E. Gibson, N. Guillo and M. J. Tozer, Tetrahedron, 1999, 55, 585-615.

5 I. Berezowska, N. N. Chung, C. Lemieux, B. C. Wilkes and P. W. Schiller, J. Med. Chem., 2009, 52, 6941-6945.

6 X. Yu, P. Talukder, C. Bhattacharya, N. E. Fahmi, J. A. Lines, L. M. Dedkova, J. LaBaer, S. M. Hecht and C. Shengxi, Bioorg. Med. Chem. Lett., 2014, 24, 5699-5703.

7 C. Solanas, B. G. de la Torre, M. Fernandez-Reyes, C. M. Santiveri, M. A. Jimenez, L. Rivas, A. I. Jimenez, D. Andreu and C. Cativiela, J. Med. Chem., 2009, 52, 664674.

8 N. Turner, Curr. Opin. Chem. Biol., 2011, 15, 234-240.

9 M. M. Heberling, B. Wu, S. Bartsch and D. B. Janssen, Curr. Opin. Chem. Biol., 2013, 17, 250-260.

10 L. Poppe and J. Rétey, Curr. Org. Chem., 2003, 7, 1297-1315. 11 L. Poppe and J. Rétey, Angew. Chem., Int. Ed., 2005, 44, 3668-3688.

12 (a) L. Poppe, Curr. Opin. Chem. Biol., 2001, 5, 512-524; (b) J. Rétey, Biochim. Biophys. Acta, 2003, 1647, 179-184.

13 B. de Lange, D. J. Hyett, P. J. D. Maas, D. Mink and F. B. J. van Assema, ChemCatChem, 2011, 3, 289-292.

14 A. Gloge, J. Zon, A. Kővári, L. Poppe and J. Rétey, Chem. Eur. J., 2000, 6, 3386-3390.

15 C. Paizs, A. Katona and J. Rétey, Chem. - Eur. J., 2006, 12, 2739-2744.

16 C. Paizs, M. I. Toşa, L. C. Bencze, J. Brem and F. D. Irimie, Heterocycles, 2011, 82, 1217-1228.

17 (a) J. H. Bartha-Vári, M. I. Toşa, F. D. Irimie, D. Weiser, Z. Boros, B. G. Vértessy, C. Paizs and L. Poppe, ChemCatChem, 2015, 7, 1122-1128; (b) J. H. Bartha-Vári, L. C. Bencze, E. Bell, L. Poppe, G. Katona, F. D. Irimie, C. Paizs and M. I. Toşa, Period. Polytech., Chem. Eng., 2017, 61(1), 59-66.

18 F. Ender, D. Weiser, B. Nagy, L. C. Bencze, C. Paizs, P. Pálovics and L. Poppe, J. Flow Chem., 2016, 6, 43-52.

19 D. Weiser, L. C. Bencze, G. Bánóczi, F. Ender, R. Kiss, E. Kókai, A. Szilágyi, B. G. Vértessy, Ö. Farkas, C. Paizs and L. Poppe, ChemBioChem, 2015, 16, 2283-2288.

20 H. A. Cooke, C. V. Christianson and S. D. Bruner, Curr. Opin. Chem. Biol., 2009, 13, 460-468.

21 S. Strom, U. Wanninayake, N. D. Ratnayake, K. D. Walker and J. H. Geiger, Angew. Chem., Int. Ed., 2012, 51, 28982902. 
22 G. G. Wybenga, W. Szymanski, B. Wu, B. L. Feringa, D. B. Janssen and B. W. Dijkstra, Biochemistry, 2014, 53(19), 3187-3198.

23 C. V. Christianson, T. J. Montavon, G. M. Festin, H. A. Cooke, B. Shen and S. D. Bruner, J. Am. Chem. Soc., 2007, 129, 15744-15745.

24 S. Pilbák, Ö. Farkas and L. Poppe, Chem. - Eur. J., 2012, 18, 7793-7802.

25 (a) D. Röther, L. Poppe, G. Morlock, S. Viergutz and J. Rétey, Eur. J. Biochem., 2002, 269, 3065-3075; (b) S. Pilbák, A. Tomin, J. Rétey and L. Poppe, FEBS J., 2006, 273(5), 1004-1019.

26 J. D. Hermes, C. A. Roeske, M. H. O'Leary and W. W. Cleland, Biochemistry, 1982, 21, 5106-5114.

27 S. L. Lovelock, R. C. Lloyd and N. J. Turner, Angew. Chem., Int. Ed., 2014, 53, 4652-4656.
28 U. Wanninayake, Y. DePorre, M. Ondari and K. D. Walker, Biochemistry, 2011, 50, 10082-10090.

29 S. Bartsch and U. T. Bornscheuer, Protein Eng., Des. Sel., 2010, 23, 929-933.

30 R. Eisenthal, M. J. Danson and D. W. Hough, Trends Biotechnol., 2007, 25(6), 247-249.

31 A. Varga, G. Bánóczi, B. Nagy, L. C. Bencze, M. I. Toşa, Á. Gellért, F. D. Irimie, J. Rétey and L. Poppe, RSC Adv., 2016, 6, 56412-56420.

32 B. Schuster and J. Rétey, Proc. Natl. Acad. Sci. U. S. A., 1995, 92, 8433-8437.

33 H. Liu and J. H. Naismith, BMC Biotechnol., 2008, 8, 91101.

34 N. A. Dima, A. Filip, L. C. Bencze, M. Oláh, P. Sátorhelyi, B. G. Vértessy, L. Poppe and C. Paizs, Stud. Univ. BabesBolyai Ser. Chem., 2016, 61, 21-34. 